\title{
Comunidades eclesiales de base
}

\author{
Pedro Trigo, \\ Centro Gumilla, \\ Caracas, Venezuela.
}

1. Horizonte de las comunidades eclesiales de base: el Vaticano II vivido desde América Latina

El concilio Vaticano II es el gran acontecimiento eclesial de los últimos liempos. En él sopló con vigor el Esplritu que renueva a la Iglesia en fidelidad creativa, ya que nos empalma a la vez con el acontecimiento de Jesús y con lo medular de nuestro liempo. Las asambleas generales del episcopado latinoamericano, que tuvieron lugar en Medellín (1968), y en Puebla (1979), constituyeron genuinas concreciones latinoamericanas del espíritu que animó al concilio, en cuanto que en ellas se expresó conjuntamente lo más medular del concilio y lo más auténtico de nuestra experiencia cristiana, en una síntesis novedosa y profética, que brinda cauces fecundos para vivir cristianamente en nuestra América. Pues bien, las comunidades cristianas de base son la creación inslitucional que simboliza y vehicula esta síntesis. Ellas recogen todo el aliento comunitario que propulsó el Vaticano II y a la vez el carácter liberador de la opción por los pobres, que caracteriza a la Iglesia latinoamericana.

\subsection{Comunidades cristianas}

El Vaticano II acabó con la identificación práctica entre Iglesia e institución eclesiástica, al establecer que la Iglesia somos todo el pueblo de Dios y no sólo la jerarquía y la vida consagrada (los curas y las monjas). Como pertenecientes al único pueblo de Dios (loos), lodos somos laicos o simplemente cristianos. El ser cristiano es lo fundamental; las determinaciones ulteriores (jerarquía, vida religiosa, seglares) son secundarias, es decir que, aunque son imprescindibles (porque el pueblo de Dios no es masa informe, sino cuerpo articulado), vienen en segundo lugar y son meramente funcionales. Funcionales significa que son 
para ayudamos a ser cristianos (es decir, hijos de Dios en el Hijo y hermanos unos de otros en el Espíritu del Hermano Jesús). Como son medios y no fines, no son definitivas. En la vida perdurable, nadie será ni cura ni religiosa ni seglar. Todos seremos simplemente hermanos y hermanas.

Si lo fundamental en la Iglesia es ser hermanos y sembrar por doquiera la fratemidad de los hijos de Dios, eso significa que en la Iglesia no hay miembros activos y miembros pasivos. Se da Iglesia cuando nos llevamos unos a otros en la fe, en el amor fratemo y en la vida cristiana. Llamamos a esta reciprocidad de dones la primera eclesialidad. Es primera porque ella constiluye a la Iglesia. La segunda eclesialidad, que cualifica y dinamiza a esta comunión primordial, acontece al llevarse muluamente los pastores y el resto del pueblo de Dios con sus múltiples carismas; es decir, cuando los pastores comulgan con los demás cristianos y el pueblo comulga con sus pastores.

Este llevarse mutuamente se da tanto en relaciones distantes (anónimas) como en relaciones cercanas (cara a cara). Las relaciones distantes son las que constituyen el cuerpo social y provienen de ponerse en común, abstrayendo los elementos individualizadores. Las relaciones cercanas, complementariamente, se dan desde la individualidad de cada quien. Sin éstas, difícilmente se dan aquéllas: si no somos capaces de amar y hacer comunidad con el hermano a quien vemos, es una ilusión pretender que amamos a todos y que mantenemos una comunión universal. Pero, por otra parte, si la comunidad se restringe a mi grupito de referencia, no sería ya una comunión personalizadora, sino mero espíritu de cuerpo, egoísmo sectario.

Teniendo en cuenta todo eslo, en Europa y Estados Unidos nacieron y aún florecen comunidades cristianas cálidas y abierlas, es decir que trascienden hacia Dios y Jesús y también hacia los que están más allá de la comunidad. Una prueba de la calidad crisliana de esta comunidad es la solidaridad con los pobres y necesitados. Esto está en auge, tanto que uno de los signos de los tiempos en el primer mundo lo constiluyen las llamadas "comunidades de solidaridad" y mil formas de voluntariado, que normalmente integran un componente comunitario.

\subsection{Comunidades cristianas de pobres y con pobres}

Pues bien, lodo este impulso del Vaticano II desembocó en América Latina en comunidades cristianas de pobres. Estas son posibilitadas y sostenidas por la solidaridad de personas de la institución eclesiástica (curas y religiosas) con los pobres. El punto de inflexión se da cuando esta solidaridad lleva a las personas de la institución eclesiástica a formar comunidad con los pobres. El cambio consiste en pasar de vivir para ellos a vivir con ellos. Al dar este paso nacen las relaciones mutuas y se instaura la primera eclesialidad: los agentes pastorales y los cristianos pobres se llevan mutuamente en la fe, en el amor fratemo y en la vida cristiana. Es decir, los agentes pastorales, sin dejar de ser tales, asumen su 
condición primordial de cristianos. Esta condición estaba opacada por la absolutización de su función sacerdotal o de su carisma religioso. Desde esa deformación (el clericalismo), el esquema relacional se hace unidireccional y vertical, aun en el caso de que sea ejercido con toda generosidad, cariño y humildad. Al reasumir la condición primordial de cristianos, los agentes pastorales pueden ya formar comunidad con los pobres. Y al ocupar su lugar la primera eclesialidad, también puede restablecerse la segunda: es decir, cuando los curas y las monjas empiezan a vivir su cristianismo con el pueblo pobre, el desempeño de la función pastoral no rompe la reciprocidad, sino que la cualifica y dinamiza.

\subsection{En el mundo de los pobres}

Pero una cosa tiene que quedar clara: los agenles pastorales no pueden formar comunidad con los pobres, sino en la casa de los pobres: en un ámbito físico, en su cultura, en su religión. Es el agente pastoral el que tiene que entrar al mundo de los pobres para que ellos formen entre sí comunidad y él sea un miembro de la comunidad de los pobres. Entrar al mundo de los pobres es ingresar a su cotidianidad. Sólo en ella, el agente pastoral puede dar su aporte sin romper la comunidad, transformándola en un grupo llevado y comandado por él. Esto entraña un modo específico de relacionarse (encuentros, no reuniones) que, sin dejar de ser articulado, debe retener la fluidez de la vida; pide que el lenguaje de la comunidad sea el que manejan los pobres entre sí. Y con el lenguaje, las preocupaciones, el horizonte emocional y mental, la problemática...

Queremos destacar dos aspectos complementarios: la importancia decisiva del agente pastoral en estas comunidades de pobres y la necesidad de que sea él el que se desplace al mundo de los pobres. Los pobres en América Latina han vivido diversas modalidades de vida comunitaria y en esa comunitariedad con frecuencia el cristianismo ha sido un elemento aglutinante y conformador. Pero, aunque no pensemos que ese comunitarismo tradicional pueda reducirse a lo que los sociólogos llaman solidaridad mecánica, sí es cierto que no es exactamente a él al que nos referimos cuando hablamos de las comunidades cristianas de pobres que florecen en nuestra lglesia latinoamericana como concreción creativa del impulso del concilio Vaticano II.

Es un hecho constatable que estas comunidades latinoamericanas de cristianos pobres han nacido con la participación de agentes pastorales. Y no sólo han nacido, sino que perduran en su dinamismo cuando el encuentro se mantiene y profundiza. Pero es igualmente constatable que cuando ese encuentro no se dio en el mundo de los pobres (es decir, en su trama vital y en su cultura, aunque aconteciera en su ámbito físico), no dio lugar a verdaderas comunidades, sino a grupos, ya que las relaciones del agente pastoral con el grupo acabaron configurándolo, disolviéndose de hecho la primera eclesialidad. Esto aconleció con frecuencia por la intermediación de los animadores, que, a la larga, recibieron las 
directrices de arriba y las comunicaron a sus compañeros en un modelo comunicacional unidireccional y de arriba abajo —que era el esquema en que desarrollaban sus relaciones con los agentes pastorales. Así pues, para que el encuentro entre agentes pastorales (curas y monjas) y el pueblo cristiano pobre no degenere en dependencia, sino que se mantenga en su condición de diálogo, en pie de igualdad, entre distintos, este diálogo debe desarrollarse en el ámbito popular. Sólo entonces resultará mutuamente enriquecedor, con tensiones por la diversidad de polos, pero por eso mismo con la posibilidad de fecundación recíproca y permanente dinamismo. Cuando el agente pastoral mantiene todo el control, desaparece, según su punto de vista, todo peligro, pero también se esfuma la vida, la creatividad; más aún, se pierde la primera eclesialidad. No hay ya Iglesia viva, a pesar de la posible buena voluntad y entrega del agente pastoral. Prevalece lo que en términos filosóficos se denomina "mala fe".

\subsection{Caracterización de las comunidades eclesiales de base}

Así pues, en estas comunidades de pobres que se mantienen en el mundo popular existen unos miembros de algún modo heterogéneos, que son los pertenecientes a la institución eclesiástica (curas y monjas). Ellos son, ante todo, cristianos como los demás, y, porque se asumen así, se sienten hermanos de los demás y se van haciendo cristianos con ellos y en el camino se van hermanando mucho más profundamente. Pero desde esta horizontalidad fundamental que se origina de ser llevados por los demás y de llevarlos a ellos, desempeñan su función ministerial o carismática y así dinamizan y enriquecen el diálogo sin quebrar su bidireccionalidad.

Existen comunidades eclesiales de base cuando acontece que el pueblo pobre y las personas de la institución eclesiástica se llevan mutuamente en su fe, en el amor fratemo y en la vida cristiana, y cuando ese conllevarse se da en el mundo de los pobres, en la casa del pueblo. Llamamos secundariamente comunidad eclesial de base a la estructura en la que normalmente se desarrolla este acontecimiento, estructura que se ha ido configurando y decantando a lo largo del tiempo, pero que dista mucho de estar consolidada, porque este encuentro de agentes pastorales con el pueblo cristiano pobre, en el seno del propio pueblo encierra tal novedad que aún está por lo general en fases intermedias.

\subsection{Las comunidades eclesiales de base, novedad histórica}

Para entrar al mundo de las comunidades eclesiales de base es preciso percatarse de su novedad radical, y por eso de la imposibilidad de que se constituyan, configuren y den de sí en menos de dos o tres generaciones. Ya es difícil percibir su verdadera naturaleza; mucho más lo será el transformamos tanto que no reduzcamos la novedad a lo que ya existe y a lo que ya somos, sino que, por el contrario, esas relaciones horizontales, hasta hoy inéditas en nuestra Iglesia, se 
vayan consolidando en estructuras organizativas y personales, que relengan y potencien lo que va surgiendo.

Queremos enfatizar que las comunidades eclesiales de base no sólo no existían hace tres décadas, sino que ni siquiera existía su posibilidad y sigue hoy sin existir en la mayoría de los ámbilos de nuestra Iglesia. Si no existe la posibilidad en muchos ambientes es porque ni se da esa trama objetivada de relaciones (es decir, costumbres, cauces, estructuras de vivencia comunitaria de fe) ni existen esos sujctos tan ganados por la primera eclesialidad y moldeados por ella que eso es lo que brota de ellos y no saben ni pueden vivir de otro modo su fe.

Por eso, el proceso de creación y consolidación de una comunidad eclesial de base es muy largo y laborioso, porque a la vez que se configura esa comunidad concreta tiene que crearse el horizonte de comunitariedad cristiana en el cual se inscribe y los sujetos que la componen. Si los sujetos se limitan a dar de lo que tienen, si no son conscientes de que tienen que ir más allá de sí mismos y de sus cauces habituales, no se pasará de los grupos de siempre con nombres diversos. Precisamente, el mayor aliciente de la comunidad eclesial de base es la novedad radical que entraña: esa necesidad de trascender, ese dolor de dar a luz una creación histórica y de redimensionarse para acuerparla y esa alegría de transformarse y renacer, y de encontrarse con otros de una manera inédita y cada vez más profunda, con olros que no son de nuestra misma carne y sangre, pero a los que reconocemos en el mismo proceso y con los que nos encontramos en el camino.

Así pues, a partir de algunos anhelos, disposiciones y propuestas, en la marcha vamos creando actitudes que nos van habilitando, que nos capacitan para que veamos como posibles cosas que antes no lo eran. Al ir realizando esas posibilidades, profundizamos las aclitudes básicas y se aumentan nuestras capacidades, con lo que surgen nuevas posibilidades. Al llevarlas a la práctica, se relanza el proceso. En este sentido fundamental, el documento de Santo Domingo afirma que los miembros de las comunidades eclesiales de base se forman adecuadamente en el mismo proceso comunitario (n. 61). Claro está que eso acontece cuando se da el conllevarse mutuamente al que venimos haciendo referencia.

\subsection{Las comunidades eclesiales de base son eclesiales cuando son de base}

El valor de las comunidades eclesiales de base radica precisamente en conservar este dinamismo de base y en reintegrar a él a la institución eclesiástica. Por eso, las comunidades eclesiales de base no son eclesiales, si no son de base. Primero y principalmente, porque la eclesialidad fundante es la primera eclesialidad: el conllevarse en la fe, en el amor fraterno y en la vida cristiana los miembros del pueblo de Dios; y porque esta reciprocidad sólo mantiene su calidad evangélica cuando tiene a pobres como sujetos privilegiados y no sólo 
como destinatarios de la acción de la comunidad. En este sentido, la palabra base nos dice que la Iglesia es de Jesús cuando es Iglesia de los pobres.

Sólo entonces se realiza la eclesialidad en el sentido secundario de diálogo cualificado entre agentes pastorales y laicos. Este diálogo viene, en segundo lugar, y si no está montado en el conllevarse cristiano, nunca será un verdadero diálogo y se recaerá en el clericalismo. Pero si mantiene su condición secundaria, entonces no expresa ningún resentimiento anticlerical o igualitarista, sino que, por el contrario, es hacerla valer. Sólo en la base manifiesta la jerarquía su pertinencia y fecundidad evangélicas. Y es claro que así lo muestra la experiencia. Si el clericalismo, como una modalidad sacralizada de patriarcalismo, oprime a los demás y aliena a los que lo practican, el servicio de la autoridad en la base (apóstoles, evangelizadores, profetas, doctores, presidentes...) es una bendición para ella y salvación y plenilicación para el buen pastor.

\section{Las comunidades eclesiales de base como encuentro histórico}

Hemos caracterizado a las comunidades eclesiales de base como un encuentro inédito: el de personas de la institución eclesiástica en la onda del Vaticano II, Medellín y Puebla con cristianos pobres en el mundo popular. El resultado de ese encuentro son comunidades de pobres a las que pertenecen también los curas y las religiosas.

\subsection{Ingredientes del encuentro}

Es fácil detectar los elementos del encuentro. Los agentes pastorales aportan fundamentalmente tres tipos de elementos. En primer lugar, el horizonte del Vaticano II leído desde América Latina: la revelación de la voluntad universal de salvación desde el reverso de la historia, que los cristianos aceplamos como evangelio y a cuyo servicio nos consagramos (eso es lo que significa que la Iglesia es sacramento universal de salvación); el redescubrimiento de la Escritura (y sobre todo de los evangelios que son su corazón) como fuente de revelación y su entrega al pueblo pobre como acto de tradición constituyente; la convicción de que la realidad histórica que vivimos es el lugar teologal por excelencia, en el que desaguan todos los demás, pero que requiere discernimiento, porque la presencia de Dios en él no es epifánica; la centralidad del seguimiento de Jesús de Nazaret en el horizonte del reino de Dios, que se siembra en esta vida, pero que se cosecha en la otra...

También aportan, en segundo lugar, un método, que consiste en la interacción de elementos analíticos (ver), hermenéuticos (juzgar) y práxicos (actuar). Decimos interacción, porque la realidad se analiza desde una posición vital y desde unas prácticas anteriores, y la iluminación de la fe está a su vez posibilitada por la praxis que abre el campo de inteligibilidad ("la luz de la vida") y condicionada posiblemente por la percepción de la situación. 
$\mathrm{Y}$ en tercer lugar, como ya estamos dando a entender, los agentes pastorales filtran también en la comunidad una determinada visión de las cosas más o menos científica o ideológica.

Los cristianos pobres aportan, ante todo, el peso de realidad que acarrea su situación. Los miembros de las comunidades eclesiales de base (como el 80 por ciento de la humanidad) no pueden dar por supuesta la vida y dedicarse (como lo hacen la mayoría de los que viven en países desarrollados y los ricos de los países empobrecidos) a prepararse y capacitarse a producir o a consumir o a descansar y disfrutar de la vida. Los privilegiados de la humanidad, cuando estudian o loman vacaciones o se reciclan o están enfermos o se jubilan, reciben la vida del cuerpo social, y además lo que ganan les da no sólo para vivir sino para satisfacer el consumismo burdo o refinado por el que la vida, según ellos, merece vivirse. Para los miembros de las comunidades eclesiales de base la preocupación, en cambio, es mantenerse en vida.

La exclusión estructural de oportunidades de vida para el pueblo tiende a introyectarse entre los pobres como exclusión mutua. El abandono se internaliza como autodesprecio y, por tanto, como hostilidad para con los que son como uno. Además la extrema tensión que produce el esfuerzo incesante por la capacitación y el trabajo, y la guerra de la competencia insolidaria, deshumanizan, alienan y tienden a expresarse en forma de violencia horizontal y de degradación humana. Los miembros de las comunidades eclesiales de base pertenecen a este mundo y sienten la presión de estos mecanismos y de estos impulsos.

La realidad es vivida por ellos como agonía, en el sentido literal de lucha de la vida contra la muerte. En esta situación en la que acecha la muerte, porque el orden establecido excluye de los medios de vida, la $v$ ida para estas personas es el empeño por mantenerse en vida, un empeño siempre cuesta arriba, y por eso, un empeño que debe ser incesantemente renovado.

Lo segundo que aportan los cristianos pobres en la comunidad es el convencimiento experiencial de que, si uno confía en Dios, siempre halla el modo de hacer frente a esta agonía con paz, con libertad, incluso con holgura y alegría, en medio de las dificultades que no cesan. Dios no es un talismán que trae suerte; la relación con él no es mágica. Pero la seguridad de que uno, pase lo que pase, está en manos de Dios da una confianza de fondo, que permite no ahogarse en los problemas, que capacita para verlos cara a cara (porque Dios tiene la última palabra) y así agotar todas las posibilidades de salida e incluso crear nuevas. También el conversar con Dios, el desahogarse con él y hasta el pelear con él, si llega el caso, esponja, consuela, incluso lleva a que se le ocurran a uno cosas.

Pero, si la fe es confianza en libertad mutua que le deja a Dios ser Dios, sin embargo la fe, como humana que es, tiene arras, signos y sacramentos. La 
religión del pobres es eminentemente sacramental; todo es rastrear signos del paso de Dios, conjurarlo humilde y rendidamente, agradecerle hermosa, incluso exquisitamente en medio de su sencillez, y presentar animosamente los dones de la propia fe, de la propia entrega. Pero los signos de fe más connotados son los milagros. Los milagros no suplen la fe, pero sí la nutren. Son indispensables, vienen cuando quiere Dios, pero cuando llegan, llenan a la persona de alegría y le dan ánimos para seguir llevando la cruz de la vida esponjadamente y con una esperanza inconmovible. Los pobres con su fe logran milagros y el milagro global de vivir esa agonía venciendo a la muerte y a la deshumanización. En verdad que la victoria que vence al mundo es la fe (1Jn 5, 4); y no sólo al mundo, sino a la propia impotencia, lan colidiana y cruelmente experimentada (Mc 9, 22-23; 2Cor 4, 7-12; 12, 7-10).

El tercer elemento que aportan los pobres en las comunidades es que esta fe de la que se vive (Hab 2, 4; Rom 1, 17) se expresa dando vida, dando de su pobreza, como Jesús que nos enriqueció con la suya $(2 \operatorname{Cor} 8,9)$. Es lo que dice Pablo: que la fe se expresa en amor solidario (Gal 5, 6). No excluimos como ingrediente lo que los sociólogos llaman "solidaridad mecánica", que se expresa en el dicho: "hoy por ti, mañana por mi". Pero sí afirmamos resueltamente que ella no da cuenta ni remotamente de este fenómeno que observamos en gente de las comunidades (y en otras personas pobres). Nosotros afirmamos que, a pesar de la naturalidad con que se da, no es un rasgo de su idiosincrasia ni de su cultura, es decir, que no lo hacen en su condición de elementos de un conjunto, llevados de la lógica global, sino como personas, en lo que la persona tiene de absolutamente único y trascendente. Es decir, que este dar al que nos referimos constituye, en cada caso, un verdadero acontecimiento, una especie de milagro de la gracia (en lenguaje teológico esıricto, una acción del Espíritu a través de la persona), que, dada la estructura encarnatoria de la acción espiritual, es fuente pura de creación cultural. Quiero insistir en lo que cuesta dar, tanto el dar puntual como el hacerse cargo más establemente de algo o de alguien. Las privaciones, estrecheces y lágrimas que comporta sólo se compensan por la experiencia de que, como decía Jesús, "hay más alegría en el dar que en el recibir" (Hech $20,35)$ y sobre todo por la experiencia fontal de que no faltará Dios al que hace un poquito con otros lo que él hace siempre con uno.

\subsection{Transformación resultante del encuentro}

Pero queremos resaltar que estos ingredientes que aportan a la comunidad, tanto los pobres como los agentes pastorales, se encuentran en la comunidad refundidos por el encuentro, cuando éste se da realmente en el mundo de los pobres y cuando llega al nivel de la primera eclesialidad, es decir, de este conllevarse como cristianos. Enlonces, el horizonte del Vaticano II, leído desde América Latina, cobra toda su densidad, su peso de revelación, que es peso de realidad, digamos su santidad. Este horizonte no es ya sólo algo recibido a base 
de estudio y trasmisión oral, algo aceptado de corazón como guía de vida. Se va convirtiendo en algo que se va descubriendo en la vida y viviendo, algo que se conoce por experiencia y de lo que por eso se puede dar testimonio. Y así se ve que "Dios ha escogido a los pobres de este mundo para hacerlos ricos en la fe" (Sant 2,5), que "donde abunda el pecado sobreabunda la gracia" (Rom 5, 20), que el evangelio de Jesús es para los pobres ( $\operatorname{Lc} 4,18 ; 7,22)$, que al Padre le ha parecido ocultar sus misterios a los sabios y entendidos y revelarlos a la gente sencilla (Le 10,21), que Dios ha querido salvar al mundo con la locura de la cruz, que es debilidad y necedad para los que no quieren entrar por este carnino, pero en la que late la sabidurfa y la fuerza de Dios (1Cor 1, 18-30)...

En el encuentro, también las concepciones más o menos científicas de los agentes pastorales se ven sometidas a prueba y se confirman, se matizan, se corrigen y se complementan. El encuentro (si de verdad es tal y, por ende, supera, como tantas veces hemos insistido, la relación ilustrada, que es constitutivamente unidireccional y vertical, es decir, altruista y pedagógica) propicia que se vaya superando el sesgo ideológico (una precomprensión de las cosas que se autoentiende, equivocadamente, como captación de ellas mismas, es decir, en el sentido más neutro de la palabra, el pre-juicio) y que vaya aflorando la verdadera teoría (la comprensión de la realidad a través de la práctica que valida o no hipótesis), que cada vez es más modesta, pero también más clara y firme.

También el método se complejiza. Ante todo, como decíamos, cambia de ritmo para no dejar afuera el ritmo de la vida, su fluencia, y para no desligar lo que se tematiza de la matriz global en la que está. $Y$ así las reuniones de la comunidad se convierten en encuentros. Una consecuencia es que a los tres elementos del método que reseñábamos se le suman otros dos: el momento de oración, que es también clima de todo el encuentro, y el de la celebración que lo corona, aunque también se hace presente a lo largo de su desarrollo. También, como pórtico y despedida, afloran los momentos de acogida mutua y comunicación vital, de encuentro propiamente dicho, y de sellar, al acabar, con diversos signos el encuentro y remitirse al encuentro en la colidianidad.

Si estas transformaciones no se dan y la reunión sigue esquemáticamente los pasos de ver, juzgar y actuar, es signo inequívoco de que no se ha dado el encuentro, de que no se está siquiera en el mundo del pobre y que la comunidad no es tal sino un grupo comandado por el agente pastoral, bien sea personalmente, bien por algún promovido que, por serlo, sigue rígidamente sus pautas. El encuentro de la comunidad, en cambio, tiene un ritmo holgado, sin que eso rebaje un punto su rigor y articulación. Pero, sobre todo, la reunión de la comunidad cristiana se desarrolla en un clima de oración, en el sentido primigenio de que se desarrolla en presencia de Dios y de que se ausculta su voluntad, pero lambién en el de que se pide, se agradece y se ofrece. Un signo de que la reunión se desarrolla a la vez en la holgura de la vida y en un ambiente de gracia es que 
no falta la celebración, no sólo que se conciertan encuentros especiales para celebrar, sino que la celebración es uno de los armónicos del encuentro y que nunca falta un tiempito dedicado a ella.

Otro elemento que con el tiempo se va añadiendo al método y que reviste bastante importancia es el de la evaluación. A la gente le gusta comentar cómo salieron las cosas y cómo va la marcha de los procesos. Cuando se encuentran cauces adecuados para sistematizar estos comentarios y sacar las consecuencias de lo que se va viendo, la gente lo agradece y se siente contenta, porque ve más claro y se enrumba mejor.

En el encuentro la fe del pobre se historiza y su empeño agónico por vivir se dinamiza. Para que esto acontezca es decisiva la lectura orante de la palabra, sobre todo de los evangelios; pero a la luz de la historia de salvación que descubre la salvación en la historia y, por tanto, el carácter histórico de la realidad. Es verdad que existe el peligro de que se combinen una lectura ideologizada de la Biblia y una visión ideologizada de la situación por parte del agente pastoral, con una religiosidad fundamentalista y mesiánica por parte del pueblo pobre. Los efectos son, entonces, explosivos y a la postre desmovilizadores y con costos humanos muy altos. Pero si el encuentro se mantiene en la matriz de la vida y si en ella se escucha realmente la palabra, el resultado es que va brotando la palabra en la gente popular, palabras como respuesta personal y por eso palabras genuinas, que hacen justicia a la realidad (la propia y la de la situación) y que proponen acciones proporcionadas y que llevan también al reconocimiento mutuo. En el mismo proceso los componentes se personalizan, fragua la comunidad y se abren al vecindario personalmente y como grupo.

Este encuentro de palabra y vida desde la fe y en el seno de la comunidad es decisivo para el pueblo pobre, tanto que va marcando un antes y un después en sus vidas. Pero no lo es menos en los agentes pastorales. La trascendencia de la palabra escuchada capacita para escuchar a Dios en la vida (los signos de los tiempos), para discernir su presencia salvadora. Pero a su vez, al tratar de ser fiel a él en la vida, haciendo triunfar en uno mismo y en su entorno la vida frente al desprecio, la opresión y la exclusión, la Biblia se abre y desborda de luz y consuelo. $\mathrm{Y}$ al ir avanzando en ambas direcciones en la presencia de los demás y en su compañía, se instaura una fratemidad sagrada, los miembros de la comunidad aprenden a respetarse y quererse y se animan a ayudarse mutuamente. El resultado es la fraternidad de los hijos de Dios.

\section{Algunas cuestiones de funcionamiento}

Lo fundamental es que se vaya dando un encuentro con los ingredientes y frutos señalados. Las modalidades del encuentro varían bastante y no se pueden reducir a fórmulas fijas. Son distintas las comunidades rurales y las suburbanas, aquellas que crecen donde la institución eclesiástica está sólidamente implantada 
y las que se levantan casi en tierra de nadie, aunque no falte la vivencia del catolicismo popular y lazos esporádicos con alguna parroquia o institución afín. También varían las formas si las comunidades eclesiales de base se dan en una cultura con bastante substrato comunitario o en otra más individualista o si acontecen en un medio muy marcado por la tradición o en otro en el que lo dominante es la apertura a lo nuevo. También es distinto que la comunidad surja a partir de una asociación apostólica o que se forme de una actividad religiosa específica, por ejemplo la catequesis familiar, o que se inicie por una propuesta explícita de formar comunidad o desde un grupo de promoción popular, aunque ligado a algún agente pastoral o que nazcan como respuesta a una situación determinada que atraviesa un grupo humano.

\subsection{Elementos de los encuentros}

Ya hemos hablado del método. Pero el mismo mélodo puede dar lugar a distintos esquemas organizativos; incluso éstos pueden cambiar a través del proceso. Por eso, en vez de referimos al esquema, nos limitaremos a enumerar una serie de elementos que, a la larga, estarán presentes en los encuentros, aunque obviamente no lodos en cada uno.

- Presentación de hechos y problemas de la vida de los miembros o de la comunidad; o, en cuanto estén sus miembros implicados, del barrio o caserío, del sindicato, la ciudad, el país...

- Aportes teóricos para esclarecer el problema; marcos de referencia, conceptualización precisa de los hechos, análisis metódico de los diversos elementos...

- Presentación de temas o puntos de reflexión de tópicos políticos, sociales, culturales, religiosos, que han ido aflorando en sucesivas reuniones, para su profundización y esclarecimiento.

- Iluminación de los problemas y de la vida por la palabra de Dios, sobre todo el evangelio, leído, escuchado y discemido. lios.

- Lectura orante corrida de la palabra de Dios, sobre todo de los evange-

- Aportes de la teología de la liberación, que recoge la tradición de la comunidad cristiana y los aportes de otras comunidades hermanas en América Latina, en cuanto sean precisos y convenientes para lo que se trae entre manos.

- Proposición de acciones individuales o del grupo o de la comunidad, acciones puntuales o encadenadas en un proceso.

- Evaluación de eslas actividades y de la marcha de la reunión y el grupo.

— Oración individual y común. Cantos. Celebraciones. 


\subsection{El tamaño de las comunidades eclesiales de base}

Un asunto, sobre el que es en extremo conveniente reflexionar, es el que se refiere a las proporciones de la comunidad. La pregunta es qué conjunto es capaz de llevar adelante este método. A nuestro modo de ver es ésta una pregunta decisiva. Nosotros pensamos que un grupo de, por ejemplo, doce personas es radicalmente insuficiente para llevar a cabo dinámicamente todo lo antedicho. A la larga o se descompone o sobrevive en la rutina o es el grupo de un líder carismático o vive como uno de los núcleos de una organización que le suminisIra materiales, personal especializado, procesos de formación...

En este caso no será ya una comunidad de base, sino una de las células de una organización (así se llame coordinadora de comunidades eclesiales de base), sea parroquial o diocesana o regional o incluso nacional. En este modelo organizativo, aunque pueden tomarse en cuenta las necesidades y deseos de las distintas células, la política se diseña en la instancia superior y ella es también la que gerencia el proceso con la mediación de los agentes intermedios, que ordinariamente se llaman animadores.

Si la comunidad ha de ser realmente de base, no vernos cómo pueda mantenerse a la larga con menos de unos cincuenta miembros. Aunque si ya pasan bastante de cien no nos parece fácil mantener la cohesión comunitaria. Así, pues, para que el dinamismo comunitario sea autosustentable se precisa una base mínima; si no, las personas se recargan demasiado y se agotan y, además, lodo se personaliza excesivamente y es difícil que llegue a cuajar la comunidad como cuerpo articulado. Pero una comunidad demasiado numerosa se convierte en una institución o en un movimiento y se diluye lo propiamente comunitario.

Para esta comunidad de la que hablamos parece demasiado desgastante que funcione en cada caso como un único cuerpo polivalente. Por eso, la comunidad sería un grupo humano articulado y, por tanto, subdividido en núcleos de proximidad física y en grupos funcionales (catequesis farniliar, escucha orante de la palabra...). Habría encuentros de cada núcleo o grupo, y otros de toda la comunidad. Por ejemplo, los primeros pueden tener lugar entre semana, y el fin de semana pueden confluir todos en una misa participada, preparada de antemano en los núcleos. También hay problemas y temas que pueden Iratarse por separado y luego en conjunto. También las fiestas estacionales (navidad y semana santa) y las locales son oportunidades para combinar la preparación en pequeños grupos y la celebración conjunta articulada. Esta misma interacción debería ocurrir para llevar la marcha de conjunto.

\section{Objetivo de las comunidades eclesiales de base: fomentar la vida fraterna de los hijos de Dios}

Acabaremos con algunas consideraciones sobre el objetivo de las comunidades eclesiales de base. El objetivo de estas comunidades es hacerse cristianos 
juntos. Nunca acabamos de hacemos cristianos; por eso, este objetivo no se restringe a una etapa preliminar, preparatoria. Es una meta inalcanzable que llena toda la vida. Por eso, éste es el único objetivo de las comunidades eclesiales de base, que se va concretando en el camino, llenándose de contenido, diversificándose internamente sin desviarse.

Hacerse cristianos significa para las comunidades eclesiales de base vivir la vida fraterna de los hijos de Dios. Vivir entre ellos y fomentarla en su entomo. De esie modo, las comunidades eclesiales de base abarcan los diversos aspeclos de la existencia desde una profunda unidad: la unidad que tiene la vida, que es lo mismo que decir la unidad del designio de Dios.

\subsection{Vida desde la fe}

Ante todo, queremos decir que se trata de la vida: de mantenerse en la vida y de que esa vida sea humana, digna, hermosa en medio de su dureza, una vida como de hijos de Dios. Para los miembros de las comunidades eclesiales de base, la sobrevivencia es el problema más absorbente. Pero esta sobrevivencia, siendo tan cuesta arriba y tan a contracorriente y consumiendo casi toda la energía disponible, no es entendida por ellos, según el paradigma dominante, como una lucha de todos contra todos para que prevalezca el más fuerte o el más sagaz o el más apoyado o el más productivo, sino como un empeño sin tregua por producir vida y por comunicarla simbióticamente. Dicho en términos paulinos, se trata de responsabilizarse cada quien de su propia vida y de ayudarse unos a otros a llevar esta carga de la vida (Gal 6, 5.2).

El saberse en manos del Dios de la vida, del Dios de la humanidad, del Dios de los pobres, del Dios Padre y Madre amoroso es lo que da esa confianza de fondo, que abre a ese horizonte positivo, en el que existe la posibilidad de vida sin sacrificar a nadie, antes ayudándose unos a otros, siendo socios en esta aventura de hacer crecer la vida en la que la competencia se sublima en emulación. Es Dios en uno el que da energías para ese empeño por la vida a pesar de todo, el que mantiene ese dinamismo de vida compartida. El compartir la fe ahonda esta dirección hasta convertirse, poco a poco, en una verdadera fratemidad, en sincero, sacrificado y tiemo amor de hermanos.

\subsection{La cotidianidad}

Esta fe que da vida se expresa obviamente en la vida. Ya dijimos que los encuentros comunitarios, incluidas las celebraciones litúrgicas, sin perder su especificidad, deben realizarse en los ritmos de la vida, deben tratar de ella y celebrarla, deben ser capaces de anudar con el misterio que la funda y no menos de contribuir a echar para adelante la vida, es decir, a que la vida dé de sí y se trascienda. Insistimos en que los encuentros y las celebraciones no pueden ser planos, no pueden transcurrir en un continuum indiferenciado de la conviviali- 
dad vecinal; por el contrario, han de poseer su propia estructura y gestualidad. Pero esta especificidad ha de mantenerse en la trama de la vida, ha de expresar que la vida es compleja y a la vez articulada.

Pero no hay comunidad eclesial de base si sus miembros sólo se encuentran en las reuniones. Se distingue una reunión de grupo de un encuentro de comunidad eclesial de base, porque ésle genera la convivencia entre los que participan de él. Esc proceso no puede acelerarse de un modo voluntarista; y cuando el punto de partida es la heterogeneidad, el desconocimiento y el recelo, el camino que va de los encuentros en la comunidad a las visitas en las casas, a la convivencia, a los servicios mutuos y a la Tamiliaridad habitual es un camino bastante largo, de años. Pero hay comunidad eclesial de base, si el camino, no obstante las dificultades, sc va haciendo. Precisamente, el gran logro de la comunidad es el surgimiento de este ámbito de confiabilidad, de compañía, de ayuda mutua, de afecto, que es capaz de sobreponerse a eventuales malentendidos o problemas, e incluso de crecer a través de ellos al procesarlos sincera y generosamente.

Esta cotidianidad nada liene que ver con la normalidad de los que pueden dar por supuesta la vida. Esa normalidad tiende a expresarse como ocio refinado o frívolo o como altruismo, o más frecuentemente como consumismo desaforado, contraparte de la entrega tensa de la producción. En todo caso, en la normalidad todo está previsto y por eso es el ámbito de lo in-irascendente, contrapuesto al modo de producción y al de lo público y lo político. Precisamente, el esfuerzo en el trabajo es para conquistar un espacio de seguridad y abundancia moldeado al gusto de cada quien. En el mundo del pobre, la cotidianidad no está scparada de la producción de la vida malerial y social. En ella se dan formas de Irabajo, además se construyen, la casa y el hábilal, se moldean las costumbres familiares y vecinales y se fraguan las esiructuras de encuentro y solidaridad. En ese mundo inacabado y amenazado, que se levanta y deteriora al mismo tiempo, en ese mundo precario e hirviente, la colidianidad está abierta a la degradación y a la trascendencia. Por eso, si la vida en buena medida se juega ahí, es normal que el Espíritu que renueva la faz de la tierra impulse a las personas de las comunidades eclesiales de base a que se encuentren en este ámbito decisivo.

\subsection{Comunidades y grupos}

La cotidianidad popular tiene una dimensión de fluidez que debe mantenerse por encima de todo, sin permitir que la sofoque ningún tipo de encuadramiento. Por eso insistíamos en que las reuniones comunitarias deben vivirse más como encuentros que como reuniones, de modo que retengan ese ritmo de la vida. Ahora queremos añadir, complementariamente, que también es normal que la cotidianidad popular, para cualificarse, dé lugar a una gama variada de encuentros en torno a acontecimientos a a problemas y no menos a la constitución de 
grupos más o menos estables para hacer frente articuladamente a carencias estructurales o para lograr mancomunadamente aspiraciones sentidas por muchos.

Por eso, los miembros de las comunidades eclesiales de base participan en diversos grupos o tienden a constituirlos, si no los hay en su medio. Esta es una experiencia de todas las comunidades eclesiales de base cuando alcanzan un mínimo de vitalidad y consistencia. Y si pasado un tiempo, los integrantes de una comunidad se satisfacen con el encuentro entre ellos y la convivencia vecinal, habría que dudar de su calidad cristiana, ya que la vida, sin perder su fluidez, tiende a articularse en torno a intereses sectoriales, y la vida compartida lleva a unirse establemente para lograrlos. Esta inslitucionalización del compromiso en la pertenencia a grupos es expresión de la madurez y seriedad con que se vive la entrega al fomento de la vida propia y de los demás.

Pero los grupos se especifican por su campo propio de dedicación y por sus tareas concretas. Por eso están abiertos a quienes desean comprometerse a ellas y de ningún modo pueden restringirse a los miembros de la comunidad eclesial de base. A la larga, pues, se da una dualidad organizativa entre la comunidad eclesial de base y los grupos. Esta dualidad, en principio, es positiva para el medio popular.

Los miembros de las comunidades eclesiales de base encuentran en los grupos un ámbito privilegiado donde expresar la fratemidad de los hijos de Dios en el esfuerzo sostenido por defender la vida y cualificarla. Si los miernbros de una comunidad eclesial de base no parlicipan en grupos, se ensimisman, se vuelven elitistas, y su vivencia cristiana pierde consistencia y densidad, se psicologiza e ideologiza; y al perder trascendencia, el grupo se atasca y tiende a enrollarse en conflictos intemos.

A su vez los grupos populares tienden a encontrar en los miembros de las comunidades eclesiales de base que pertenecen a ellos un firme apoyo para estabilizarse y perdurar dinámicamente, superando dificultades y procesando conflictos, al inscribir la dinámica del grupo en un horizonte más amplio y de más largo plazo en el que la gratuidad es un ingrediente decisivo. En efecto, en los grupos no es infrecuente que se llegue a un punto en el cual los individuos piensen que dan más de lo que reciben o que el costo de funcionamiento es mayor que el beneficio que les reporta. Este razonamiento puede desembocar en la retirada del grupo, en su división o incluso en su disolución. En estas coyunturas, los miembros de las comunidades eclesiales de base pueden aportar al grupo una lógica más complexiva, no restringida al esquema de "te doy para que me des", y al superar el puro utilitarismo logran una utilidad mayor a largo plazo y sobre todo una verdadera fecundidad histórica. 
Hace veinte años se llegó a subtitular un libro: "Las comunidades de base reinventan la Iglesia". Hoy ¿tendremos que confesar que esa apreciación fue un espejismo? Ciertamente que en nuestro país, las comunidades eclesiales de base son el granito de mostaza, la semilla más pequeña. ¿Tendrán la misma potencialidad que la de la parábola evangélica? Para quien esto escribe, han sido vehículo de gracia y salvación: a través de ellas me voy haciendo cristiano y en ellas he visto crecer y madurar a gente popular que hoy son hermanos míos y que me estimulan con su testimonio y con su afecto. A nivel de nuestra Iglesia local y de la Iglesia latinoamericana, creo que ellas son una oportunidad excepcional que Dios nos da (kairós). ¿La dejaremos pasar?

\section{Bibliografía mínima}

a) Documentos del magisterio

Lumen Gentium 9; 26; Evangelii Nuntiandi 58; Redemptoris Missio 51; Medellín 6:13-14; 8:10; 15:10-12, 32; Puebla 9, 96-98, 156, 261-262, 629631, 638-643, 648-649; Santo Domingo 60-63, 101, 142.

b) Sobre el horizonte de las comunidades eclesiales de base

R. Velasco, La Iglesia de Jesús, Estella, 1992, 254-266, 369-384.

K. Rahner, Cambio estructural de la Iglesia, Madrid, 1974, 71-74, 132-145.

J. Sobrino, El principio-misericordia, Santander,1992, 214-215, 224-226, 239-245.

J. Comblin, Antropología cristiana, Madrid, 1985, 19-37.

c) Sobre las comunidades eclesiales de base

J. Marins, Comunidad eclesial de base. Origen, contenido y perspectivas, Bogotá, 1977.

J. Marins-Trevisan, Comunidades eclesiales de base. La Iglesia en pequeño, Bogotá, 1996.

R. Muñoz, "Experiencia popular de Dios y de la Iglesia", en Cambio social y pensamiento cristiano en América Latina. Madrid, 1993, 161-179.

Sedoc, Una Iglesia que nace del pueblo, Salamanca, 1979.

L. Boff, Eclesiogénesis: las comunidades de base reinventan la Iglesia, Santander, 1979, 9-73.

Id., Iglesia: carisma y poder, Santander, 1982, 197-217.

A. Zenteno, Un camino de humildad y esperanza (Las comunidades eclesiales de base en México), México, 1983.

C. Boff, "Fisonomía de las comunidades eclesiales de base", Concilium 164, 1981, 90-98. 
G. Iriarte, ¿Qué es una comunidad eclesial de base? Quito, 1989.

M. Azevedo, Comunidades eclesiales de base, Madrid, 1979.

P. Trigo, "Comunidades eclesiales de base en Venezuela", SIC 449 (1982) 412416. 